\title{
Clinical Value of Detecting Tumor Endothelial Marker 8 (ANTXRI) as a Biomarker in the Diagnosis and Prognosis of Colorectal Cancer
}

This article was published in the following Dove Press journal: Cancer Management and Research

\author{
Łukasz Pietrzyk (iD) ${ }^{1,2}$ \\ Agnieszka Korolczuk ${ }^{3}$ \\ Małgorzata Matysek ${ }^{4}$ \\ Marcin B Arciszewski iD ${ }^{4}$ \\ Kamil Torres' \\ 'Department of Didactics and Medical \\ Simulation, Faculty of Medicine, Medical \\ University of Lublin, Lublin, Poland; \\ ${ }^{2}$ Department of General, Oncological \\ and Minimally Invasive Surgery, Ist \\ Military Clinical Hospital with the \\ Outpatient Clinic in Lublin, Lublin, \\ Poland; ${ }^{3}$ Department of Clinical \\ Pathomorphology, Faculty of Medicine, \\ Medical University of Lublin, Lublin, \\ Poland; ${ }^{4}$ Department of Animal Anatomy \\ and Histology, Faculty of Veterinary \\ Medicine, University of Life Sciences in \\ Lublin, Lublin, Poland
}

Background: Despite the continuous improvements in prevention and detection of colorectal cancer (CRC), there is an urgent need to find a sensitive, specific, and noninvasive biomarker to improve the early diagnosis and prognosis of CRC. We aimed to evaluate the tissue TEM8 expression and the serum TEM8 concentration in CRC patients.

Methods: The study enrolled $42 \mathrm{CRC}$ patients and 35 controls. Immunohistochemical staining was performed to assess the TEM8 tissue expression, whereas the serum TEM 8 concentration was evaluated with the ELISA assay.

Results: The expression of TEM8 observed in all primary colorectal tumor samples was significantly correlated with the TNM stages and the presence of lymphovascular invasion. The serum TEM8 concentration was significantly higher in CRC patients than in the controls. The TEM8 level was strongly associated with the TNM stage, depth of invasion, and lymph node and distant metastasis. Patients with a high serum TEM8 concentration had a worse overall survival (OS) rate than CRC patients with a low serum TEM8 level.

Conclusion: TEM8 may serve as a biomarker for the diagnosis of CRC and it has value in predicting the prognosis of patients with CRC.

Keywords: colorectal cancer, tumor endothelial marker 8, biomarker, ANTXR1, angiogenesis

\section{Introduction}

Colorectal cancer (CRC) is one of the most common malignancies of the digestive system. It is the third most frequently diagnosed cancer globally and the fourth leading cause of cancer-related deaths worldwide. ${ }^{1,2}$ Regular screening allows the detection of CRC at the early stage, which is crucial in providing effective therapies and leads to a considerable reduction of CRC-related deaths. ${ }^{3}$ Despite the continuous improvements in prevention and detection of CRC, approximately $15-25 \%$ of newly diagnosed patients have metastases at the time of diagnosis. ${ }^{4}$

Therefore, there is an urgent need to find a sensitive, specific, and noninvasive molecule that could work as a biomarker to improve the diagnosis and prognosis of CRC. Carbohydrate antigen 19-9 (Ca 19-9) serum marker is used most commonly for CRC diagnosis; however, its serological measurement is not recommended for screening and diagnostic identification of early CRC stages. ${ }^{5,6}$ Nowadays, increasing interest is aroused by various non-invasive body-fluid-based biomarkers. Recently, assessing circulating methylated septin 9 (mSEPT9) DNA in blood has
Correspondence: Łukasz Pietrzyk Department of Didactics and Medical Simulation, Faculty of Medicine, Medica University of Lublin, Chodźki 4, Lublin, 20-093, Poland

Tel +48 8I4485020

Email lukasz.pietrzyk@wp.pl 
been approved as an alternative non-invasive test for $\mathrm{CRC}$ screening; however, to date, there is no consensus on the diagnostic algorithm of mSEPT9 PCR assay. ${ }^{7}$

The continual unregulated proliferation of cancer cells is necessary for the development of cancer. Tumor growth and spread depend on several processes, including proliferation, angiogenic capacity, and metastatic capability of cancer cells. ${ }^{8}$ Tumor cells receive oxygen and nutrients through neovasculature. Angiogenesis is therefore recognized as a crucial step for the proliferation and survival of cancer cells. ${ }^{9,10}$ New blood vessels also contribute to invasion of surrounding normal tissue and spread of cancer cells throughout the body. ${ }^{11}$ Compared to normal vessels, tumor blood vessels exhibit an abnormal pattern of organization and function. ${ }^{12}$ There is growing evidence that this irregular and nonhierarchical tumor neovasculature expresses unique molecules named tumor endothelial markers (TEMs), which can discriminate between typical and atypical blood vessels. ${ }^{13}$ Moreover, it is becoming increasingly apparent that TEMs may be useful for the development of effective cancer therapy. ${ }^{14,15}$

In 2000, assessing the gene expression in ECs derived from different stages of human colorectal tumors, St. Croix et al recognized 46 TEMs. ${ }^{16}$ The studies on the TEM subcategories (TEM1-TEM9) revealed their signaling functions and pilot role in remodeling ECs into cells characteristic for the angiogenic state. Subsequent surveys documented many of these TEMs in mice models. ${ }^{17,18}$

Among TEMs, TEM8 (tumor endothelial marker 8) also known as Anthrax Receptor 1 (ANTXR1) is highly up-regulated in the tumor endothelium and is expressed in diverse cancer types, including colorectal cancer. ${ }^{19-21}$ The high antibody reactivity of this transmembrane glycoprotein with tumor microvessels suggests its potential role as a biomarker for identification of tumor-associated microvessels in CRC. Moreover, a significant increase in blood TEM8 mRNA levels was described in CRC patients compared to controls, which indicates that TEM8 can be a candidate for a marker of the presence of tumor and a marker of tumor invasiveness and spread. ${ }^{21,22}$ In addition, there are shreds of evidence that blocking TEM8 might disrupt tumor angiogenesis. The application of an anti-TEM8 antibody-drug conjugate in preclinical settings showed its potential to boost cancer therapy and therefore suggested TEM8 as an antigenic target for immunotherapy in many cancer types. ${ }^{23,24}$

In this study, we evaluated the expression of the TEM8 protein in colorectal cancer tissue and non-malignant colorectal tissue as well as the serum TEM8 concentration in colorectal cancer patients. Finally, we assessed the association of TEM8 tissue expression and serum concentration with the TNM classification and the overall survival in the patients.

\section{Methods}

\section{Patients}

We enrolled 42 patients (male:female $=27: 15$ ) who underwent surgery for colorectal cancer in 2014 (JanuaryDecember) in the Department of General, Oncological, and Minimally Invasive Surgery of the 1st Military Clinical Hospital with the Outpatient Clinic in Lublin, Poland. The mean age of the CRC patients was $68.83 \pm$ 10.99 years (range: $44-84$ ) and BMI was $28.31 \pm 3.47 \mathrm{~kg} /$ $\mathrm{m} 2$ (range: $20.26-36.75 \mathrm{~kg} / \mathrm{m} 2$ ).

All CRC cases were confirmed by a pathologist in the histopathological examination. Tumor staging was classified according to TNM staging classification proposed by the American Joint Committee on Cancer Staging. All patients were included in the follow-up with respect to survival status. The follow-up sessions were scheduled in 6-month periods, with the last one being a 36-month postoperative telephone call or an on-site visit.

Additionally, thirty-five healthy volunteers with normal colonoscopy reports (male:female $=19: 16$; mean age 64 \pm 8.76 years, range: $43-80$ years; mean BMI $26.86 \pm$ $3.76 \mathrm{~kg} / \mathrm{m}^{2}$, range: $21.86-33.27 \mathrm{~kg} / \mathrm{m}^{2}$ ) were recruited from the Outpatient Clinic of our hospital. These control group blood donors were complementary with the CRC patients in terms of the age and BMI.

The Ethical Committee of the Medical University of Lublin, Poland (decision no. KE-0254/240/2008) approved the study. All the patients became acquainted with the objective of the study and signed consent forms prior to the beginning of any procedures. The study was performed in accordance with the 1975 Declaration of Helsinki (6th revision, 2008).

\section{Immunohistochemical Staining}

The samples of tumor tissues and normal colonic mucosa from the surgical margin were collected after surgery in the CRC patients. The distant normal colonic mucosal samples were free from tumor cells, as confirmed by histopathological examination. Tissue samples were processed into paraffin blocks.

The paraffin blocks were cut into 5 - $\mu$ m-thick sections with a microtome and placed on silanized glass slides 
(superfrostplus, Germany). Immunohistochemical staining (peroxidase-antiperoxidase method) of the slides was performed according to the following protocol. First, the paraffin was removed. To this end, the sections were washed in xylene ( 3 times for $15 \mathrm{~min}$ ). Next, the slides were rehydrated. The rehydration procedure involved sequential incubation of the slides with a graded series of ethyl alcohol. Then, the slides were washed in distilled water. The antigen retrieval protocol involved placement of the slides in a container with citrate buffer $(\mathrm{pH}=6.0)$ and heating to $97^{\circ} \mathrm{C}(3 \times 7 \mathrm{~min})$ in a microwave oven $(800 \mathrm{~W})$. To avoid and reduce nonspecific background staining, a protein blocker (Anti-Rabbit IgG, A0545, Sigma, Germany) was dropped onto the sections incubated for $10 \mathrm{~min}$ at standard room temperature (RT). In the next step, the slides were rinsed in PBS ( $\mathrm{pH}=7.4)$ twice (15 min each). Excess buffer was dried out, and primary
TEM8 (ANTXR1) antibodies (dilution 1:100; Sigma, Germany) were added to the sections and incubated overnight at $4^{\circ} \mathrm{C}$. The slides were rinsed in wash buffer $(4 \times 15$ min) and covered with secondary biotinylated goat antipolyvalent plus sera (Mouse and Rabbit Specific HRP Plus (ABC) Detection IHC Kit, Ab93697) for 10 min (RT). Then, the sections were washed 4 times (RT) in PBS and incubated with streptavidin peroxidase plus (Ab93697mouse and rabbit specific HRP (ABC) detection IHC Kit; Abcam, USA) for another $10 \mathrm{~min}$ (RT). The 3,3'diaminobenzidine (DAB, Vector, USA) chromogen was applied for the visualization of primary antisera. The working solution of DAB was added to the slides and the process was observed under LM (light microscope). Finally, the slides were rinsed in distilled water. Counterstaining (for $20 \mathrm{~min}$ ) was performed with Mayer's hematoxylin. After washing in distilled water,
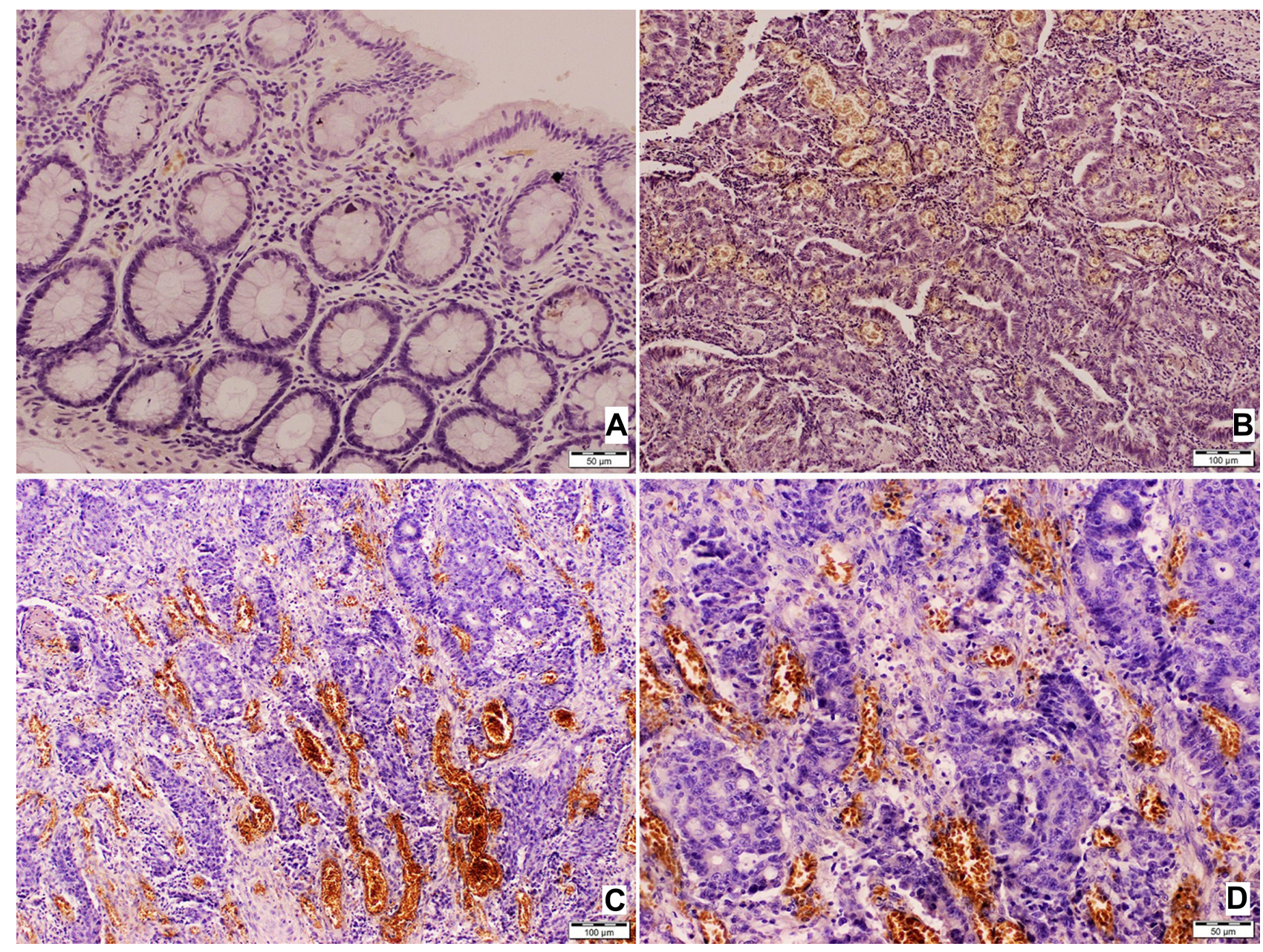

Figure I TEM8 expression in normal colonic mucosa and colorectal cancer tissue. (A) Normal colonic mucosa of the surgical margin (free of tumor), no TEM8 expression; (B) colonic adenocarcinoma. Immunohistochemical expression of TEM 8 within endothelial cells of vessels, low expression; (C and D) colonic adenocarcinoma. Immunohistochemical expression of TEM 8 within endothelial cells of vessels, high expression. 
the slides were dehydrated in ethyl alcohol series, cleared in xylene, mounted in DPX, and coverslipped. The specificity of the antibodies used was verified by a negative control, in which primary antibodies were replaced with the same concentrations of appropriate non-immune IgG.

The classification of the cases into low and high TEM 8 expression groups was based on the study carried out by Albasri et al. ${ }^{25}$ The level of TEM8 overexpression was calculated by combining the immunostaining intensity with the percentage of immune-reactive cells. The immunostaining intensity of TEM8 in the primary tumor and distant normal mucosa tissues was graded as strong $=2$, weak $=1$, or negative $=0$ (no staining). The immunoreactivity was semi-quantitatively evaluated as negative ( $0 \%$ of stained cells), 1 ( $1-10 \%$ of cells), 2 (positive in $11-50 \%$ of cells), or 3 (positive in $\geq 51 \%$ of cells). The final expression score was determined as follows: (score 0$),+($ score 1-3), and ++ (score 4-5). For statistical analysis, the cases scored + were classified as the low expression group, while the high expression group included cases scored as ++.

\section{Enzyme-Linked Immunosorbent Assay (ELISA)}

Venous blood samples were collected before the surgery in the CRC patients and as part of routine examination in the healthy individuals. Blood was centrifuged at $1000 \mathrm{x}$ g for $10 \mathrm{~min}$ at $2-$ $8^{\circ} \mathrm{C}$. The serum was immediately transferred into a clean polypropylene tube and stored at $-80^{\circ} \mathrm{C}$. Serum TEM 8 was quantified with an enzyme-linked immunosorbent assay (ELISA) according to the manufacturer's instructions (MyBioSource, catalog no. MBS941904). The detection range and sensitivity limits of the ELISA assay were 0.625 $\mathrm{pg} / \mathrm{mL}-4000 \mathrm{pg} / \mathrm{mL}$ and $<15.6 \mathrm{pg} / \mathrm{mL}$, respectively. Briefly, $100 \mu \mathrm{L}$ of the standard and sample were added into each well of the ELISA plate and incubated for $2 \mathrm{~h}$ at $37^{\circ} \mathrm{C}$. After incubation and removing the liquid from each well, $100 \mu \mathrm{L}$ of biotin-antibody were added into the wells and incubated for $1 \mathrm{~h}$ at $37^{\circ} \mathrm{C}$. Plate washes were performed with an automatic washer TriNEST (Perkin Elmer). Next, $100 \mu \mathrm{L}$ of HRP-avidin were added into the wells and incubated for $1 \mathrm{~h}$ at $37^{\circ} \mathrm{C}$. After the incubation, the plate was washed automatically and $90 \mu \mathrm{L}$ of the TMB substrate were added. Next, the plate was incubated for $15 \mathrm{~min}$ at $37^{\circ} \mathrm{C}$. Finally, $50 \mu \mathrm{L}$ of the stop solution were added into the wells. The absorbance was read at $450 \mathrm{~nm}$ with the use of a microplate reader Victor (Perkin Elmer). The standard curve was plotted by reducing the data using
Table I Relationship Between the Tissue TEM8 Expression Level and Clinicopathological Features in 42 CRC Patients

\begin{tabular}{|c|c|c|c|c|}
\hline \multirow[t]{2}{*}{ Variables } & \multirow[t]{2}{*}{ Patients n (\%) } & \multicolumn{2}{|c|}{ TEM8 Expression } & \multirow[t]{2}{*}{$p$-value } \\
\hline & & Low n (\%) & High n (\%) & \\
\hline \multicolumn{5}{|l|}{ Tumor site } \\
\hline Colon & $22(52.4)$ & $8(19.0)$ & $14(33.3)$ & 0.337 \\
\hline Rectum & $20(47.6)$ & $7(16.7)$ & $13(31.0)$ & \\
\hline \multicolumn{5}{|l|}{ Tumor size } \\
\hline$<5.0 \mathrm{~cm}$ & $19(45.2)$ & $4(9.5)$ & $15(35.7)$ & 0.110 \\
\hline$\geq 5.0 \mathrm{~cm}$ & $23(54.8)$ & II (26.2) & $12(28.6)$ & \\
\hline \multicolumn{5}{|l|}{ TNM stage } \\
\hline $1+\|$ & $24(57.1)$ & $12(28.6)$ & $12(28.6)$ & 0.021 \\
\hline III + IV & $18(42.9)$ & $3(7.1)$ & $15(35.7)$ & \\
\hline \multicolumn{5}{|c|}{ Depth of invasion (T stage) } \\
\hline$T_{1}$ & $5(11.9)$ & $3(7.1)$ & $2(4.8)$ & 0.036 \\
\hline $\mathrm{T}_{2}$ & $9(21.4)$ & $6(14.3)$ & $3(7.1)$ & \\
\hline$T_{3}$ & $16(38.1)$ & $6(14.3)$ & $10(23.8)$ & \\
\hline $\mathrm{T}_{4}$ & $12(28.6)$ & $0(0.0)$ & $12(28.6)$ & \\
\hline \multicolumn{5}{|c|}{ Lymph node metastases ( $\mathrm{N}$ stage) } \\
\hline Absent $\left(\mathrm{N}_{0}\right)$ & $25(59.5)$ & $14(33.3)$ & II (26.2) & 0.022 \\
\hline $\begin{array}{l}\text { Present } \\
\left(\mathrm{N}_{1+2}\right)\end{array}$ & $17(40.5)$ & I (2.4) & $16(38.1)$ & \\
\hline \multicolumn{5}{|c|}{ Distant metastasis ( $M$ stage) } \\
\hline Absent $\left(M_{0}\right)$ & $37(88.1)$ & $14(33.3)$ & $23(54.8)$ & 0.054 \\
\hline Present $\left(M_{1}\right)$ & $5(11.9)$ & I (2.4) & $4(9.5)$ & \\
\hline \multicolumn{5}{|c|}{ Lymphovascular invasion } \\
\hline Absent & $26(61.9)$ & $13(30.9)$ & $13(31.0)$ & 0.017 \\
\hline Present & $16(38.1)$ & $2(4.8)$ & $14(33.3)$ & \\
\hline
\end{tabular}

Notes: Significant $p$-values are indicated in bold; $p$-value in $\mathrm{Chi}^{2}$ test.

computer software capable of generating a four-parameter logistic (4-PL) curve-fit.

Serum Ca 19-9 was assessed using a Cobas 6000 biochemistry analyzer (Roche Diagnostic, North America) in the Diagnostic Laboratory in our hospital.

\section{Statistical Analysis}

The analyses were performed using SPSS version 17.0 software (IBM SPSS, Chicago, IL). Descriptive statistics was used to present the data (mean \pm standard deviation; SD). The Mann-Whitney $U$-test and the Kruskal-Wallis test was used to assess the differences in serum TEM 8 levels between the CRC patients and the controls as well as the serum TEM8 level and clinicopathological parameters of the CRC patients. The relationship between tissue TEM8 expression and 
clinicopathological parameters was evaluated using Chisquared test and two-sided Fisher's exact test. Evaluation and comparison of the diagnostic value of serum TEM8 concentrations were performed using the receiver operating characteristics (ROC) curve and the area under the curve (AUC). Overall patient survival was analyzed with the Kaplan-Meier method followed by a log-rang test. For all tests, values of $p<0.05$ were considered statistically significant.

\section{Results}

\section{Immunohistochemical Expression of TEM8 and Its Correlation with Clinicopathological Features}

Immunohistochemical expression of TEM8 was observed in the cytoplasm of endothelial cells of vessels in all primary colorectal tumor samples (Figure 1A-D). The non-specific reaction was also present in erythrocytes within the vessels. Low focal expression (Figure 1B) was observed in 15 cases (35.7\%), while 27 cases (64.3\%) showed high TEM8 expression (Figure 1C and D). A majority of the normal colonic mucosa samples $(n=33 ; 95.6 \%)$ did not show TEM8 expression (Figure 1A).

The correlation of the TEM8 expression in tissues with clinicopathological features is shown in Table 1. The TEM8 expression was correlated with the TNM stage, the $\mathrm{T}$ stage, the $\mathrm{N}$ stage, and the presence of lymphovascular invasion $(p<0.05)$.

\section{Serum TEM8 Concentration and Its Correlation with Clinicopathological \\ Features}

The mean TEM8 concentration in serum was significantly higher in patients with CRC compared to the controls $(228.46 \pm 110.27 \mathrm{pg} / \mathrm{mL}$ vs $41.54 \pm 20.72 \mathrm{pg} / \mathrm{mL} ; p<$ 0.001 ; Figure 2). To assess the usefulness of TEM8 in the early detection of CRC, the TEM8 serum level in the early-stage (stage I + II) CRC patients was compared with the noncancer individuals. The mean TEM8 concentration was significantly elevated in the serum of patients with early-stage colorectal cancer (stage I + II) compared to the control group $(171.33 \pm 90.01 \mathrm{pg} / \mathrm{mL}$ vs $41.54 \pm$ $20.72 \mathrm{pg} / \mathrm{mL} ; p<0.001)$.

The relationship between the serum TEM8 concentration and clinicopathological features in the CRC patients is presented in Table 2. The analysis revealed a significant relationship between the mean serum TEM8 level and the TNM stage, depth of invasion ( $\mathrm{T}$ stage), and lymph node and distant metastasis ( $\mathrm{N}$ and $\mathrm{M}$ stage, respectively) and the presence of lymphovascular invasion in tumor tissue.

The serum TEM8 concentration was not related to the tumor location (colon vs rectum), tumor size $(<5.0 \mathrm{~cm}$ vs $\geq 5.0 \mathrm{~cm}$ ) and the presence of lymphovascular invasion in the CRC tissue ( $p=0.960$ for tumor site; $p=0.105$ for tumor size; $p=0.594$ for lymphovascular invasion).

No significant association was noted between the TEM8 level in blood serum and the age and BMI in the CRC

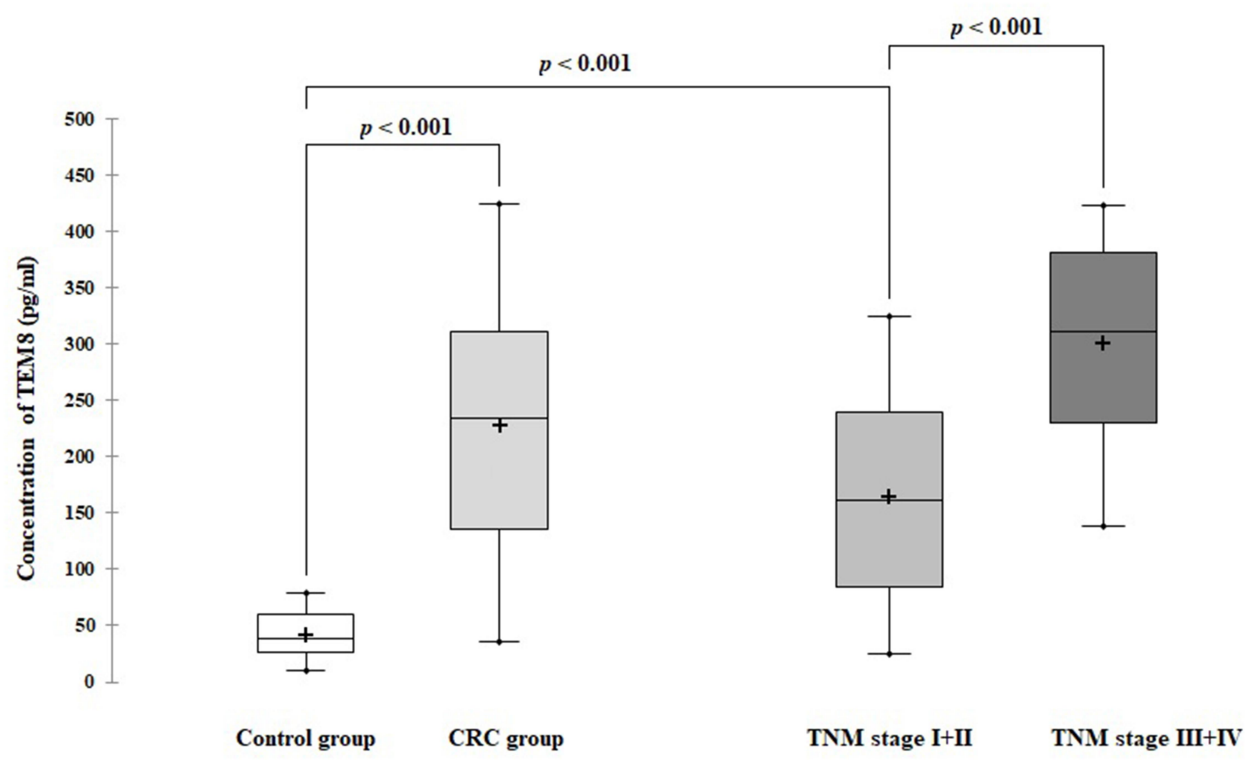

Figure 2 Serum TEM8 concentration in colorectal cancer (CRC) patients and control groups. 
patients (for age $<60$ vs $\geq 60$ : $186.36 \pm 103.40$ vs $249.50 \pm$ $109.25 \mathrm{pg} / \mathrm{mL} ; p=0.067$; for normal BMI vs obese patients: $212.35 \pm 98.33$ vs $252.01 \pm 111.31 \mathrm{pg} / \mathrm{mL} ; p=0.411$ ).

\section{Suitability of the Serum TEM8 Concentration in CRC Detection}

To evaluate the possible clinical application of TEM8, we compared TEM8 to Ca 19-9 biomarker. The mean value of Ca 19-9 was significantly higher in the CRC patients than in the controls ( $14.45 \pm 7.62$ vs $8.05 \pm 6.75 \mathrm{ng} / \mathrm{mL} ; p<0.001)$.

Next, we analyzed the ROC curves of serum TEM8 and Ca 19-9 in the CRC patients (Table 3). As shown in Figure 3A, TEM8 predicted the diagnosis of the CRC patients with an area under the curve (AUC) of 0.969 ( $95 \%$ confidence interval [CI]: $0.935-1.000 ; p<0.001)$ at a cutoff point of $80.48 \mathrm{pg} / \mathrm{mL}$. This cutoff point provided $90.5 \%$ sensitivity and $96.7 \%$ specificity. The AUC for Ca $19-9$ was 0.758 $(95 \%$ CI $0.643-0.873, p<0.001)$ with the cutoff point at the level of $7.98 \mathrm{ng} / \mathrm{mL}$. This cutoff point was characterized with $71.4 \%$ sensitivity and $82.9 \%$ specificity (Figure $3 \mathrm{~B}$ ).

\section{Serum TEM 8 Concentrations and Overall Survival of CRC Patients}

All 42 CRC patients from January 2014 to December 2014 included in this study were followed up for 36 months. The 36-months overall survival (OS) rate was $47.62 \%$. CRC patients with high serum TEM8 concentrations $(\geq 80.48 \mathrm{pg} / \mathrm{mL}$ ) had a worse overall survival (OS) rate than those with low serum TEM8 levels $(<80.48 \mathrm{pg} / \mathrm{mL}$; Figure 4). All patients with low TEM8 levels $(n=5)$ survived the observational period. The OS time for patients with high TEM concentrations $(\mathrm{n}=37)$ was 26.75 months (95\% CI: 24.25-29.24).

\section{Discussion}

A number of diagnostic techniques and tests have been developed and improved over the last 20 years; however, still most CRC patients already have lymph node or distant metastases at the time of diagnosis. The commonly used Ca 19-9 marker is regarded as to have low sensitivity (only 20-40\%) for detecting CRC at early stages. $^{26,27}$ Therefore, improving methods to detect the presence of early-stage CRC is a particularly challenging problem. The discovery of an effective non-invasive molecule would be crucial and positive for patients. ${ }^{28}$ Recently, increasing interest and enthusiasm have been expressed about new biomarkers (TEMs) as tools for
Table 2 Correlation of the Serum TEM8 Concentration with Clinicopathological Features in 42 CRC Patients

\begin{tabular}{|c|c|c|c|}
\hline Variables & $\begin{array}{l}\text { Patients } \\
\text { n (\%) }\end{array}$ & $\begin{array}{c}\text { Serum TEM8 Concentration } \\
\text { Mean } \pm \text { SD }(\mathrm{pg} / \mathrm{mL})\end{array}$ & $p$-value \\
\hline \multicolumn{4}{|l|}{ Tumor site } \\
\hline Colon & $22(52.4)$ & $227.04 \pm 122.98$ & \multirow[t]{2}{*}{$0.960^{\mathrm{a}}$} \\
\hline Rectum & $20(47.6)$ & $230.02 \pm 97.55$ & \\
\hline \multicolumn{4}{|l|}{ Tumor size } \\
\hline$<5.0 \mathrm{~cm}$ & $19(45.2)$ & $200.81 \pm 108.95$ & \multirow[t]{2}{*}{$0.105^{\mathrm{a}}$} \\
\hline$\geq 5.0 \mathrm{~cm}$ & $23(54.8)$ & $256.11 \pm 107.00$ & \\
\hline \multicolumn{4}{|l|}{ TNM stage } \\
\hline $1+11$ & $24(57.1)$ & $171.33 \pm 90.01$ & \multirow[t]{2}{*}{$<0.001^{\mathrm{a}}$} \\
\hline $\mathrm{III}+\mathrm{IV}$ & $18(42.9)$ & $304.62 \pm 87.26$ & \\
\hline \multicolumn{4}{|c|}{ Depth of invasion (T stage) } \\
\hline$T_{1}$ & $5(11.9)$ & $60.98 \pm 21.28$ & \multirow[t]{4}{*}{$<0.001^{\mathrm{b}}$} \\
\hline $\mathrm{T}_{2}$ & $9(21.4)$ & $126.47 \pm 32.15$ & \\
\hline $\mathrm{T}_{3}$ & $16(38.1)$ & $238.23 \pm 38.17$ & \\
\hline $\mathrm{T}_{4}$ & $12(28.6)$ & $361.69 \pm 40.71$ & \\
\hline \multicolumn{4}{|c|}{ Lymph node metastases ( $\mathrm{N}$ stage) } \\
\hline $\begin{array}{l}\text { Absent } \\
\left(\mathrm{N}_{0}\right)\end{array}$ & $25(59.5)$ & $169.20 \pm 89.67$ & \multirow[t]{2}{*}{$<0.001^{\mathrm{a}}$} \\
\hline $\begin{array}{l}\text { Present } \\
\left(\mathrm{N}_{1+2}\right)\end{array}$ & $17(40.5)$ & $315.60 \pm 74.42$ & \\
\hline \multicolumn{4}{|c|}{ Distant metastasis (M stage) } \\
\hline $\begin{array}{l}\text { Absent } \\
\left(M_{0}\right)\end{array}$ & $37(88.1)$ & $210.12 \pm 103.13$ & \multirow[t]{2}{*}{$0.002^{\mathrm{a}}$} \\
\hline $\begin{array}{l}\text { Present } \\
\left(M_{1}\right)\end{array}$ & $5(11.9)$ & $364.17 \pm 52.61$ & \\
\hline \multicolumn{4}{|c|}{ Lymphovascular invasion } \\
\hline Absent & $26(61.9)$ & $218.80 \pm 108.40$ & \multirow[t]{2}{*}{$0.594^{\mathrm{a}}$} \\
\hline Present & $16(38.1)$ & $241.32 \pm 114.53$ & \\
\hline
\end{tabular}

Notes: Significant $p$-values are indicated in bold; ${ }^{a} p$-value in Mann-Whitney U-test; ${ }^{b} p$-value in Kruskal-Wallis test.

Abbreviations: TEM8, tumor endothelial marker 8; TNM, tumor-node-metastasis.

early detection and prognosis of CRC. ${ }^{29,30}$ Therefore, we focused on the novel candidate, ie, TEM8, and tried to assess the suitability of this glycoprotein as a biomarker of early diagnosis, progression, and prognosis of CRC patients. To this end, we targeted the TEM8 assessment at the level of tissue expression and serum concentration.

The expression of TEM8 in all primary tumor tissues with high immunoreactivity was observed in more than $50 \%$ of samples and in two cases of distant normal mucosa. The exclusive expression of TEM 8 in tumor tissue observed in our study seems to be in line with other literature reports. For example, as demonstrated by 
Table 3 Diagnostic Value of Serum TEM8 and Ca 19-9 in CRC Patients

\begin{tabular}{|l|c|c|c|c|c|c|}
\hline Factor & Cutoff Value & Sensitivity (\%) & Specificity (\%) & 95\% Cl & AUC & Youden Index \\
\hline TEM8 & 80.48 & 90.5 & 96.7 & $0.935-1.000$ & 0.969 & 0.872 \\
\hline Ca 19-9 & 7.98 & 71.4 & 82.9 & $0.643-0.873$ & 0.758 & 0.543 \\
\hline
\end{tabular}

Abbreviations: TEM8, tumor endothelial marker 8; Ca 19-9, carbohydrate antigen; $\mathrm{Cl}$, confidence interval; AUC, area under the curve.

immunohistochemical staining, the overall distribution of TEM8 was more widespread in invasive breast cancer tissue relative to normal background tissue. ${ }^{21}$ The TEM 8 protein expression profile increased also in gallbladder cancer tissues compared to non-cancerous tissue. ${ }^{31}$ Similarly, TEM8 represented a highly specific expression pattern for human colorectal cancer tissues and was not detected in the endothelium of normal colonic mucosa. ${ }^{18}$

Our study equivocally demonstrated that the TEM 8 tissue expression significantly positively correlated with the TNM stage, depth of invasion (T stage), and lymph node and distant metastases ( $\mathrm{N}$ and $\mathrm{M}$ stage). This supports the previous findings, which also evidenced that the expression of TEM8 considerably increased with the tumor stage (T2 vs T3 and T2 vs T4) in gallbladder cancer tissues. ${ }^{31}$ Similarly, an increase in TEM8 transcript copies in colon cancer tissue in the advanced stage of CRC compared to the early stage were documented by Ramli et al. ${ }^{22}$ The biological mechanism of the TEM8 overexpression in cancer tissues is still unknown. However, an increase in the TEM8 expression that correlates with the T, $\mathrm{N}$, and $\mathrm{M}$ stages suggests that the TEM8 glycoprotein can be viewed as a promising marker of the presence of CRC and a marker of tumor invasiveness and spread.

A

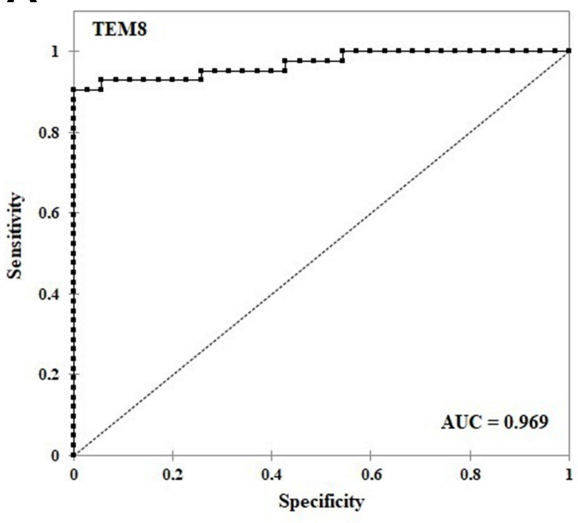

Further, we measured the TEM8 concentrations in serum samples and evidenced that the mean serum concentration of the protein was considerably higher in the CRC patients than in the healthy controls. Our results are therefore consistent with a previous study that evidenced significantly higher circulating mRNA levels of TEM8 in peripheral blood of CRC patients compared to healthy controls. $^{22,32}$

An interesting finding of our study was that the mean serum concentration of TEM8 was already higher in the CRC subjects with the early stages (TNM stage I+II) compared to the healthy individuals. This observation and the fact that the TEM8 sensitivity and specificity for CRC detection was higher than that of commonly used serum marker (Ca 19-9) suggest that TEM8 is a potential diagnostic biomarker and can be considered for early CRC diagnosis.

The TEM8 serum levels correlated with the clinicopathological features of the CRC patients, ie, the higher TEM8 serum concentrations were closely related to the TNM stage, tumor invasion depth, and lymph node metastases. These relations indicate that TEM8 plays an important role in cancer progression. Moreover, the positive correlation between the TEM8 serum concentration
B

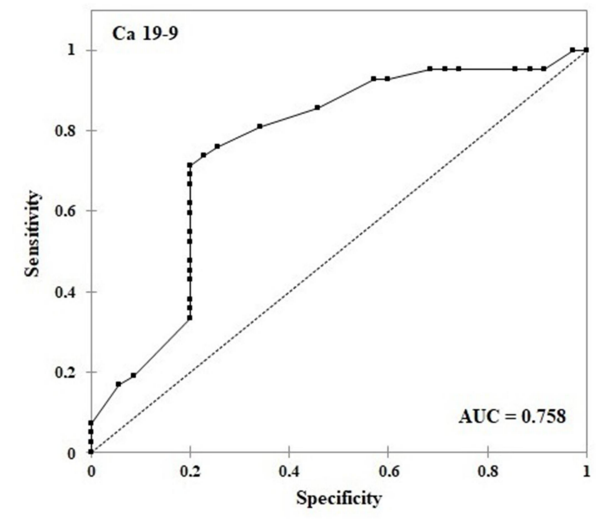

Figure 3 ROC curves of TEM8 and Ca 19-9 in CRC patients. (A) TEM8; (B) Ca 19-9. 


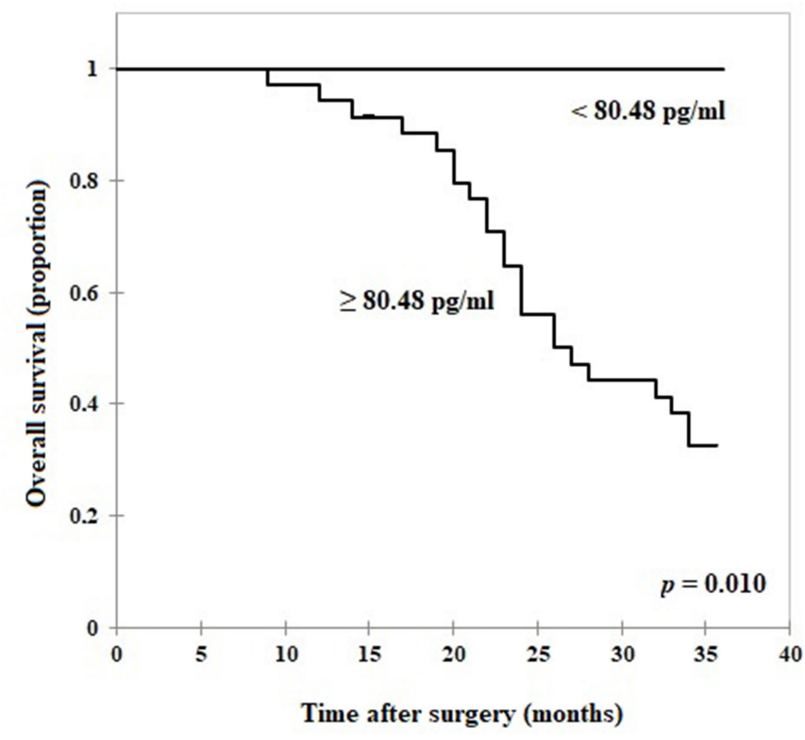

Figure 4 Relation of serum TEM8 concentrations to the overall survival time in CRC patients.

and the M stage suggests that TEM8 may be a potential marker of distant metastases in CRC patients. These observations are consistent with the study conducted by Opoku-Darko et al, who documented that TEM8 overexpression was associated with breast cancer cells that exhibited a more aggressive phenotype and increased ability to form lymph node and distant metastases, ie, to lungs. 33

We observed that the serum TEM 8 concentration was associated with the prognosis of the CRC patients. Those with high TEM8 levels $(\geq 80.48 \mathrm{pg} / \mathrm{mL})$ had a worse overall survival (OS) rate than the CRC patients with low serum TEM8 levels $(<80.48 \mathrm{pg} / \mathrm{mL})$. High TEM8 levels were typical for patients with advanced tumor and with the presence of lymph node and distant metastases. Such progression of the disease predisposes to poorer prognosis. ${ }^{21,32,33}$

Since reliability and validity in research are essential for the interpretation of results, the criteria (age, BMI) for the members of the control group were the same as for the CRC patients. In the experimental group, CRC was confirmed after colorectal screening by colonoscopy, and neither chemotherapy nor radiotherapy was conducted before the surgical procedure. On average, the blood samples were taken approximately two weeks after the CRC diagnosis in each patient. However, we found several limitations in the present study, which should be treated as preliminary research, and upcoming surveys should be focused on several issues. First, our study was performed on a limited number of CRC individuals (only 42 patients were enrolled) from a single center. In the future, a study involving several hospitals/clinics covering a larger population should be carried out to avoid overestimation of the sensitivity and specificity of TEM8. Secondly, the blood was drawn only before the surgery; therefore, further explorations have to be extended, ie, the blood analyses should be performed in at least two time-points (before and after the surgery). Thirdly, we did not assess the disease-free survival time as the information from the patients and their families was arguable. In particular, they had problems with declaration concerning the time point for the beginning/ recurrence of the cancer. Thus, statistical analysis and results do not cover the disease-free survival time. Finally, the 36-month follow-up of the CRC patients might also be seen as a limitation. It would have been more reliable to have a longer time of observation, ie, 60 months. However, in the present study, the 36-month follow-up facilitated collecting data from all the patients. Extension of observation time seemed unreliable and would have influenced the statistical analysis due to the decrease in the number of the participants.

\section{Conclusion}

In summary, tissue overexpression and elevated serum TEM8 levels play a pivotal role in the development and progression of CRC. TEM8 has better sensitivity and specificity than the routinely used marker Ca 19-9. Detection of serum TEM8 may thus serve as a diagnostic biomarker and clinical predictor for outcomes in patients with CRC. The shorter average survival time in the CRC patients with the high serum TEM8 concentration may suggest a predictor role of TEM8 in the poor prognosis of CRC patients. We also expect that the results of our study will serve as a basis for further investigations of TEM8. In particular, the research should be focused on the biology and importance of the TEM8 glycoprotein for colon cancer diagnosis, progression, and prognosis.

\section{Acknowledgments}

This research was funded by Medical University of Lublin, Poland, grant number MNmb230 to Ł.P. and DS495 to K.T.

Authors would like to thank Prof. Anna Torres MD, $\mathrm{PhD}$, for the agreement to perform the analytical analyses 
of the studied parameters in the Laboratory of Biostructure, Medical University of Lublin, Poland.

\section{Disclosure}

The authors declare no conflicts of interest for this work.

\section{References}

1. Bray F, Ferlay J, Soerjomataram I, Siegel RL, Torre LA, Jemal A. Global cancer statistics 2018: GLOBOCAN estimates of incidence and mortality worldwide for 36 cancers in 185 countries. CA Cancer $J$ Clin. 2018;68:394-424. doi:10.3322/caac.21492

2. Xu G, Zhou Y, Zhou F. Development and validation of an immunityrelated classifier of nine chemokines for predicting recurrence in stage I-III patients with colorectal cancer after operation. Cancer Manag Res. 2018;10:4051-4064. doi:10.2147/CMAR.S174452

3. Zhong W, Yu Z, Zhan J, et al. Association of serum levels of CEA, CA199, CA125, CYFRA21-1 and CA72-4 and disease characteristics in colorectal cancer. Pathol Oncol Res. 2015;21:83-95. doi:10.1007/ s12253-014-9791-9

4. van der Geest LG, Lam-Boer J, Koopman M, Verhoef C, Elferink MA, de Wilt JH. Nationwide trends in incidence, treatment and survival of colorectal cancer patients with synchronous metastases. Clin Exp Metastasis. 2015;32:457-465. doi:10.1007/ s10585-015-9719-0

5. Lech G, Slotwinski R, Krasnodebski IW. The role of tumor markers and biomarkers in colorectal cancer. Neoplasma. 2014;61:1-8. doi:10.4149/neo_2014_003

6. Wang P, Li C, Zhang F, Ma X, Gai X. Clinical value of combined determination of serum $\mathrm{B} 7-\mathrm{H} 4$ with carcinoembryonic antigen, osteopontin, or tissue polypeptide-specific antigen for the diagnosis of colorectal cancer. Dis Markers. 2018;2018:4310790. doi:10.1155/ 2018/4310790

7. Ma ZY, Law WL, Ng EKO, et al. Methylated septin 9 and carcinoembryonic antigen for serological diagnosis and monitoring of patients with colorectal cancer after surgery. Sci Rep. 2019;9:10326. doi:10.1038/s41598-019-46876-4

8. Naumov GN, Akslen LA, Folkman J. Role of angiogenesis in human tumor dormancy: animal models of the angiogenic switch. Cell Cycle. 2006;5:1779-1787. doi:10.4161/cc.5.16.3018

9. Baluk P, Hashizume H, McDonald DM. Cellular abnormalities of blood vessels as targets in cancer. Curr Opin Genet Dev. 2005;15:102-111. doi:10.1016/j.gde.2004.12.005

10. Folkman J, Kerbel R. Role of angiogenesis in tumor growth and metastasis clinical translation of angiogenesis inhibitors. Semin Oncol. 2002;29:15-18. doi:10.1053/sonc.2002.37263

11. Yamashita K, Watanabe M. Clinical significance of tumor markers and an emerging perspective on colorectal cancer. Cancer Sci. 2009;100:195-199. doi:10.1111/j.1349-7006.2008.01022.x

12. Nagy JA, Chang SH, Dvorak AM, Dvorak HF. Why are tumour blood vessels abnormal and why is it important to know? $\mathrm{Br}$ $J$ Cancer. 2009;100:865-869. doi:10.1038/sj.bjc.6604929

13. Pietrzyk $Ł$. Biomarkers discovery for colorectal cancer: a review on tumor endothelial markers as perspective candidates. Dis Markers. 2016;2016:4912405. doi:10.1155/2016/4912405

14. Frankel AE, Carter C, Kuo SR, Woo JH, Mauldin J, Liu JS. TEM8 targeted cancer therapy. Anticancer Agents Med Chem. 2011;11:983-992. doi:10.2174/187152011797927643

15. Zhang Y, Guo J, Zhang XL, et al. Antibody fragment-armed mesoporous silica nanoparticles for the targeted delivery of bevacizumab in ovarian cancer cells. Int $J$ Pharm. 2015;496:1026-1033. doi:10.1016/j.ijpharm.2015.10.080
16. St Croix B, Rago C, Velculescu V, et al. Genes expressed in human tumor endothelium. Science. 2000;289:1197-1202. doi:10.1126/ science. 289.5482.1197

17. Seaman S, Stevens J, Yang MY, Logsdon D, Graff-Cherry C, St Croix B. Genes that distinguish physiological and pathological angiogenesis. Cancer Cell. 2007;11:539-554. doi:10.1016/j.ccr.2007.04.017

18. Carson-Walter EB, Watkins DN, Nanda A, Vogelstein B, Kinzler KW, St Croix B. Cell surface tumor endothelial markers are conserved in mice and humans. Cancer Res. 2001;61:6649-6655.

19. Sun M, Li H, Liu J, Ning L, Zhao D, Liu S. The relationship between TEM8 and early diagnosis and prognosis of lung cancer. Minerva Med. 2020. doi:10.23736/S0026-4806.20.06444-7

20. Wang CX, Xiong HF, Wang S, et al. Overexpression of TEM8 promotes ovarian cancer progression via $\mathrm{Rac} 1 / \mathrm{Cdc} 42 / \mathrm{JNK}$ and MEK/ERK/STAT3 signaling pathways. Am $J$ Transl Res. 2020;12:3557-3576

21. Høye AM, Tolstrup SD, Horton ER, et al. Tumor endothelial marker 8 promotes cancer progression and metastasis. Oncotarget. 2018;9:30173-30188. doi:10.18632/oncotarget.25734

22. Rmali KA, Watkins G, Harrison G, Parr C, Puntis MCA, Jiang WG. Tumour endothelial marker 8 (TEM-8) in human colon cancer and its association with tumour progression. Eur $J$ Surg Oncol. 2004;30:948-953. doi:10.1016/j.ejso.2004.07.023

23. Duan HF, Hu XW, Chen JL, et al. Antitumor activities of TEM8-Fc: an engineered antibody-like molecule targeting tumor endothelial marker 8. J Natl Cancer Inst. 2007;99:1551-1555. doi:10.1093/jnci/ $\operatorname{djm} 132$

24. Szot C, Saha S, Zhang XM, et al. Tumor stroma-targeted antibody-drug conjugate triggers localized anticancer drug release. J Clin Invest. 2018;128:2927-2943. doi:10.1172/JCI120481

25. Albasri AM, Elkablawy MA, Hussainy AS, Yousif HM, Alhujaily AS. Impact of cyclooxygenase-2 over-expression on the prognosis of colorectal cancer patients. An experience from Western Saudi Arabia. Saudi Med J. 2018;39:773-780. doi:10.15537/ smj.2018.8.22837

26. Sun F, Peng HX, Gao QF, et al. Preoperative circulating FPR and CCF score are promising biomarkers for predicting clinical outcome of stage II-III colorectal cancer patients. Cancer Manag Res. 2018;10:2151-2161. doi:10.2147/CMAR.S167398

27. Stiksma J, Grootendorst DC, van der Linden PW. CA 19-9 as a marker in addition to CEA to monitor colorectal cancer. Clin Colorectal Cancer. 2014;13:239-244. doi:10.1016/j.clcc.2014.09.004

28. Ogunwobi OO, Mahmood F, Akingboye A. Biomarkers in colorectal cancer: current research and future prospects. Int $J \mathrm{Mol} \mathrm{Sci}$. 2020;21:5311. doi:10.3390/ijms21155311

29. Pietrzyk $Ł$, Wdowiak P. Endosialin (TEM1) as a diagnostic, progression, and prognostic serum marker for patients with colorectal cancer-a preliminary study. Cancer Control. 2020;27:1073274820903351. doi:10.1177/1073274820903351

30. Pietrzyk $Ł$, Wdowiak P. Serum TEM5 and TEM7 concentrations correlate with clinicopathologic features and poor prognosis of colorectal cancer patients. Adv Med Sci. 2019;64:402-408. doi:10.1016/j. advms.2019.07.001

31. Maurya SK, Tewari M, Kumar M, Thakur MK, Shukla HS. Expression pattern of tumor endothelial marker 8 protein in gallbladder carcinomas. Asian Pac J Cancer Prev. 2011;12:507-512.

32. Raeisossadati R, Farshchian M, Ganji A, et al. Quantitative analysis of TEM-8 and CEA tumor markers indicating free tumor cells in the peripheral blood of colorectal cancer patients. Int J Colorectal Dis. 2011;26:1265-1270. doi:10.1007/s00384-011-1230-8

33. Opoku-Darko M, Yuen C, Gratton K, Sampson E, Bathe OF. Tumor endothelial marker 8 overexpression in breast cancer cells enhances tumor growth and metastasis. Cancer Invest. 2011;29:676-682. doi:10.3109/07357907.2011.626474 


\section{Publish your work in this journal}

Cancer Management and Research is an international, peer-reviewed The manuscript management system is completely online and includes open access journal focusing on cancer research and the optimal use of a very quick and fair peer-review system, which is all easy to use. preventative and integrated treatment interventions to achieve improved Visit http://www.dovepress.com/testimonials.php to read real quotes outcomes, enhanced survival and quality of life for the cancer patient.

from published authors. 